\title{
Projeto Exagri - \\ Informação para produtores e trabalhadores ru- rais do estado de São Paulo, Brasil
}

\section{Janeti L. Bombini de Moura}

Diretora da Divisão de Biblioteca e Documentação - DIBD. Escola Superior de A gricultura Luiz de Q ueiroz - Esalq/U SP. Coordenadora do Projeto Exagri

E-mail: jlbmoura@ carpa.ciagri.usp.br

\section{Nilce T. Puga-N ass}

Supervisora da Seção de Publicações - DIBD/Esalq/USP

Gerente do Projeto Exagri

E-mail: ntpnass@ carpa.ciagri.usp.br

\section{A mélia Silveira}

Professora titular da U niversidade Federal de Santa C atarina. D outora em Ciências da Comunicação - U niversidade de São Paulo - USP. PósDoutora em Ciências da Informação - Universidad Complutense de M adrid. Consultora do Projeto Exagri

\section{Fernando A . da Silveira R ocha (in memorian)}

Professor titular aposentado da U niversidade Federal de V içosa. Ph.D. em Sociologia Rural - University of W isconsin. Consultor do Projeto Exagri

\section{Resumo}

Este relato apresenta a experiência da Divisão de Biblioteca e Documentação (DIBD), da Escola Superior de Agricultura Luiz de Queiróz - Esalq, da USP, no desenvolvimento de um projeto de informação denominado Exagri, que disponibilizou o acesso à literatura agropecuária, em nível de extensão rural, para produtores e trabalhadores rurais do estado de São Paulo. Apresenta os resultados da parceria entre a universidade e as organizações de produtores rurais.

\section{Palavras-chave}

Informação agrícola; Produtor rural; Trabalhador rural; Base de dados.

This report presents a pioneer experience of the Divisão de Biblioteca e Documentação - DIBD

\begin{abstract}
(Library and Documentation Division), of the Escola Superior de Agricultura "Luiz de Queiroz" - Esalq ("Luiz de Queiroz" Agriculture College - São Paulo University), in developing an information project, named Exagri, which provided to farmers and rural workers from São Paulo State, accessing to farming and livestock literature, at a rural extension level. It presents the results of the partnership between University and rural producer organizations.
\end{abstract}

\section{Keywords}

Agricultural information; Farmers; Rural worker; Data base.

\section{IN TRODUÇÃ O}

No Brasil, apesar dos diversos esforços empreendidos ao longo do tempo, por instituições públicas e privadas, e da existência de inúmeras bases de dados bibliográficas que indexam a literatura da área de ciências agrárias, persistem carências de informação em setores estratégicos como 0 da agropecuária, especialmente para produtores e trabalhadores rurais.

Essascarências, particularmente evidentes no quese refere ao acesso e disponibilidade de informação, foram sistematicamente detectadas em função das consultas de produtores rurais brasileiros à Escola Superior de A gricultura "Luiz de Q ueiroz" (Esalq), da U niversidade de São Paulo (USP), nos últimos 20 anos. Versando geralmente sobre questões técnicas específicas, as consultas foram recebidas pela diretoria da Esalq e encaminhadas aos departamentose à D ivisão de Biblioteca e D ocumentação (DIBD), dessa Escola, para atendimento às demandas informacionais.

Em face das dificuldades da própria D IBD/Esalq/U SP em obter literatura em linguagem simples e de fácil compreensão para colocar à disposição dos produtores e trabalhadores rurais brasileiros, visto 0 acervo constituirse, basicamente, de material técnico-científico direcionado para comunidade universitária, foi desenvolvido um projeto especificamente voltado para a provisão de informação nasáreas de agropecuária, nutrição humana, educação rural e desenvolvimento rural para este tipo de cliente.

Este Projeto, intitulado Base Exagri, foi submetido à avaliação da Fundação W. K. Kellogg em 1994, sendo aprovado no ano seguinte. 


\section{O PROJETO}

0 projeto, com duração prevista de três anos, foi iniciado em agosto de 1995, tendo os seguintes objetivos específicos:

1) coletar e tratar a literatura brasileira, de caráter extensionista, produzida a partir de 1990, centralizando os documentosna DIBD/Esalq/U SP;

2) implantar uma base de dados bibliográfica denominada Exagri, contendo a literatura de extensão coletada e tratada anteriormente;

3) colocar a base no A lerta Exagri à disposição dos produtores e trabalhadores rurais por meio dos órgãos intermediários, tais como associações de produtores, cooperativas agrícolas, sindicatos rurais e órgãos de extensão;

4) conscientizar a comunidade técnica agronômica da Esalq/USP sobre a necessidade de produzir textos adequados à população rural.

Como primeira ação efetiva do Projeto, foram contatadas as associações de produtores, sindicatos rurais, cooperativas agrícolas e de crédito das regiões de Campinas, M arília e R egistro, por meio de uma carta convite.

A s regiões escolhidas foram definidas ten do em vista que Piracicaba, onde se localiza geograficamente a Esalq/USP, está na região agrícola de $C$ ampinas. $A$ região de $M$ arília, devido à Esalq/USP, com o apoio da Fundação W .K. K ellogg desenvolveu, na oportunidade, outros projetosnesse local. A região de Registro, por tratar-se de uma das mais carentes do estado de São Paulo.

A pós o contato inicial, foram recebidas respostas imediatas de 13 entidades. 0 s dirigentes dessas organizações participaram de uma reunião na Esalq/U SP em dezembro de 1995, onde se fixou, de acordo com o número de associados de cada organização, um limite máximo de clientes que constituíram o grupo de controle. Este grupo iniciou com 279 produtores e trabalhadores rurais indicados pelas entidades. Gradativamente, outras organizações foram incorporadas ao projeto, ampliando-se, em agosto de 1997, para 17 entidades e 345 participantes.

Foram estabelecidos critérios de participação, tanto para as organizações como para os usuários individuais. Os critérios de participação das organizações foram (a) ter personalidade jurídica; (b) ter sede própria ou alugada; (c) ter estatuto e regimento registrados; (d) ter uma diretoria ou corpo de dirigentes; (e) promover reuniões regulares; (f) ter telefone e /ou fax; ( $g$ ) ter no mínimo 30 filiados. Entre os critérios de participação dosusuários, constaram (a) ser alfabetizado; (b) ser associado, sindicalizado ou cooperado; (c) ser produtor ou trabalhador rural; (d) ter endereço acessível aos correios; (e) querer participar.

Desde a implantação do projeto, foram realizadas seis reuniões com os dirigentes das organizações participantes, docentes da Esalq/USP, assessores, estagiários e outros convidados, com o objetivo de discutir as ações, acompanhar e avaliar o desenvolvimento do projeto. A coordenação do projeto constituiu um Conselho Consultivo representado por docentes da Esalq/USP, incluindo o diretor da instituição, que se reúne duas vezes ao ano. Conta ainda com a consultoria de especialistas brasileiros nas áreas de sociologia rural e de marketing da informação.

\section{A BASE EXAGRI}

Como segunda ação, foram estabelecidos critérios de seleção da literatura relacionada às quatro áreas de abrangência do Projeto Exagri, ou seja, agropecuária, nutrição humana, educação rural e desenvolvimento rural. 0 critério inicial foi estabelecer a inclusão da literatura publicada a partir de 1990. O s demais critérios foram os de selecionar publicações em: a) idioma: português; b) linguagem: textos simples e acessíveis, ilustrados com desenhos e fotos, para facilitar a compreensão; c) elementos de editoração da publicação de caráter extensionista; d) produzidos por editoras editoras ou entidades credenciadas na área (material de autoria de técnicos ou autores de reconhecida competência).

A Base Exagri, atualmente, contém cerca de 5.500 registros de materiais bibliográficos e multimeios. Foi desenvolvida a partir do sistema de gerenciamento de banco de dados relacional M icrosoft A ccess 95, buscando o desenvolvimento de um banco de dados em ambiente $W$ indows, que proporcionasse flexibilidade em termos de implementação do sistema e da utilização de imagensilustrativas. A complexidade da informação para o cliente não letrado foi atenuada com a inclusão de alguma forma visual de comunicação para auxiliar o uso da informação. Para assegurar a qualidade desta base, em face do perfil peculiar dos segmentos do projeto, a interação com o usuário do aplicativo de manutenção da base foi avaliada em sua facilidade de uso (ergonomia), por meio do emprego da técnica de avaliação heurística. Esta técnica procura identificar as características que ferem 
critérios e recomendações ergonômicas e que provavelmente representariam barreiras para a utilização adequada da Base Exagri. D esta forma, pode-se assegurar que a operação do referido aplicativo se dará com um nível reduzido de incidentes e erros, o que trará, certamente, maior produtividade e satisfação de uso para o cliente.

\section{O ALERTA EXAGRI}

Tomando-se como premissa básica que o produtor e 0 trabalhador rural, em geral, não estão habituados ao uso de tecnologias de informação, desconhecendo, muitas vezes, as formas de acesso à Internet, bases de dados etc., iniciaram-se os contatos com o grupo de controle, por meio do envio do A lerta Bibliográfico elaborado a partir da Base Exagri, que possui periodicidade bimestral e contém 27 referências bibliográficas.

A té o A lerta nํ7, de janeiro de 1997, as cópias dos artigos eram fornecidas gratuitamente. A partir deste número, os usuários passaram a receber apenas cinco cópias de artigos gratuitos e a pagar as cópias dos documentos excendentes.

Foram também produzidos quatro $A$ lertas $E$ speciaisde fitas de vídeo e distribuídos somente aos dirigentes das organizações.

A fim de aumentar a compreensão da informação dos A lertas, os el ementos bibliográficos foram organizados em um formato diferenciado e ilustrativo, buscando-se facilitar sua identificação, no macroassunto. A ilustração representou a comunicação visual do assunto principal do documento indexado, estando presente, junto à referência bibliográfica, um resumo do documento. U m exemplo da referência bibliográfica utilizada no Alerta Exagri pode ser visualizado a seguir:

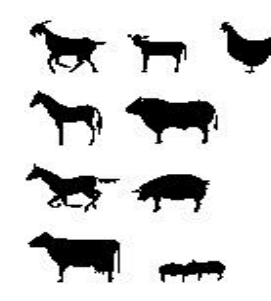

Código 1:

A utor: Bezerra, Título do A rtigo:

Título da Revista:

Local de Publicação: São Paulo, SP

Volume:

Número:

Paginação:

M ês de publicação: novembro

Resumo : a cana-de-açúcar enriquecida com uréia e enxofre ganha cada vez maior espaço no cocho como alternativa barata para alimentar o gado na seca.
A ssim, os produtores e trabalhadores rurais integrantes do grupo de controle receberam, nos últimos dois anos, um total de $15 \mathrm{~A}$ lertas. Em anexo aos A lertas, foi enviado ao cliente, sistematicamente, um formulário, contendo 0 pedido de cópia e a avaliação do próprio A lerta.

Este formulário serviu não só para evidenciar os artigos de maior interesse dos usuários, como para mostrar os assuntos mais demandados.

De forma geral, os assuntos solicitados nos A lertas voltaram-se para defesa vegetal/fitossanidade, produção animal/zootecnia, pesca/aquicultura, solos e agricultura sustentável. 0 número médio de solicitações por A lerta foi de 374 documentos.

No formulário de pedidos de cópia, pôde ser verificado, por meio de avaliação constante, que, dos 15 A lertas distribuídos, os de números 4, 7 e 10 tiveram, respectivamente, os maioresíndices de solicitação, sendo que os assuntos mais demandados voltaram-se para nutrição humana/dietética, engenharia rural e produção vegetal.

A inda como forma de avaliação do A lerta Exagri, no período de 7 a 11 de agosto de 1996, foram visitados 11 municípios das três regiões de atuação do projeto. Com 0 apoio dos dirigentes das cooperativas, associações e sindicatos, foram entrevistados por dois estagiários do Projeto Exagri, especialmente treinados para este fim, 56 produtores rurais. Este procedimento teve por objetivo detectar mudanças sociais e aperfeiçoamento de técnicas e de conhecimentos nas propriedades e atividades rurais, por meio da informação disseminada nosA lertas.

D o total dos entrevistados, $66 \%$ solicitaram cópias e $43 \%$ se utilizaram dos artigos para adoção de técnicas e de conhecimentos nas propriedades e atividades rurais. Destacaram-se como as mais citadas: a) implantação de técnicas de minhocultura; b) mudançasnos procedimentos no controle de carrapatos e na adubação demilho; c) na aplicação de calcário na cultura do maracujá, na formulação de rações para galinhas, no combate à formiga cortadeira e à broca da bananeira, além de melhorias na forma de administração da propriedade rural.

$D$ ando continuidade à avaliação do $\mathrm{A}$ lerta E xagri, de julho a setembro de 1997 foi realizada uma pesquisa buscando apontar as características, reações comportamentais de mercado e o potencial de consumo ou o montante de absorção da in formação veiculada no A lerta Exagri. A pesquisa utilizou como instrumento de coleta de dados o questionário estruturado, com questões fechadas e 


\section{Janeti L. B ombini de M oura / N ilce T . Puga-N ass / A mélia Silveira / Fernando A. da Silveira R ocha}

abertas. A população-alvo foi constituída pelos participantes do grupo de controle, escolhidos de forma intencional, nos estratos de clientes assíduose reais, sendo estes os que solicitaram cópias em todos e/ou na maioria dos sete primeiros A lertas recebidos. A intenção da amostra foi a de obter respostas de clientes que estão familiarizados com o A lerta Exagri, quanto às variáveis de segmentação geográfica, demográfica, socioeconômica, comportamento do consumidor e tipo de produto, em termos de benefícios esperados.

Estes clientes assíduos somaram oito pessoas e os clientes reais um número de 174, perfazen do 182 indivíduos. Este número de 182 clientes representa $52,8 \%$ dos 345 componentes do grupo atual de controle. Dos 182 indivíduos envolvidos na pesquisa, 84,0\% devolveram 0 questionário preenchido.

A análise estatística foi realizada com o auxílio do Statistical A nalysis System (SA S). A sprincipais perguntas que nortearam a pesquisa foram:

1) Q uais as características dos clientes do Projeto Exagri quanto à escolaridade, condição ocupacional (atividade profissional), tamanho da propriedade (em hectares), localização geográfica, entidade a que estão filiados e volume de uso de informação da Base Exagri?

2) Q uais os assuntos de maior interesse dos clientes do Projeto Exagri?

3) Q ual a relação entre as características dos clientes do Projeto Exagri e os assuntos de maior interesse?

4) Q uais os assuntos contemplados nosA lertas Exagri que continuam sendo demandados pelos clientes do Projeto?

5) Q uais as soluções encontradas e os procedimentos de mudança e aperfeiçoamento de técnicas e de conhecimentos adotados nas propriedades e atividades rurais baseados na informação dos A lertas?

6) Q ual o valor atribuído aos A lertas como fonte de informação?

\section{7) Q uais os benefícios esperados do A lerta Exagri?}

O s resultados evidenciaram que os clientes do Projeto Exagri, quanto à escolaridade, constituem segmentos de mercado distintos, onde predominam dois grupos: $43,8 \%$ elementos com terceiro grau completo ou incompleto e $34,6 \%$ com primeiro grau completo e incompleto.
Q uanto à condição ocupacional (atividade profissional), predominam os proprietários rurais,com $67,3 \%$ do total.

Q uanto ao tamanho da propriedade, há relativo equilíbrio, sendo $39,8 \%$ os que têm de 5 a 30 hectares e $47,0 \%$ de 31 a mais de 100 hectares.

Q uanto à localização geográfica ea entidade a que pertence o cliente do Projeto Exagri, destaca-se o município de Capivari, SP, por meio da Cooperativa dos Plantadores de Cana da Região de Capivari Ltda. (Canacap), que apresentou o maior número de respondentes da pesquisa, bem como o maior número clientes assíduos e reais no projeto, com $16,3 \%$ elementos.

O s assuntos de maior interesse foram horticultura $(12,5 \%)$, grandes culturas $(11,4 \%)$, bovinocultura $(11,1 \%)$, fruticultura $(10,6 \%)$, piscicultura $(8,8 \%)$ e avicultura (7,6\%).

Por meio de histogramas tridimensionais, pode-se afirmar que, em relação à horticultura, o nível de escolaridade dos clientes é menor, sendo eles predominantemente do estrato de clientes reais. A condição ocupacional (atividade profissional) é de arrendatários ou trabalhadores rurais, não havendo tendência quanto ao tamanho da propriedade.

Para grandes culturas, há indicação de maior interesse dos clientes reais, também com escolaridade menor, não havendo tendência para uma condição ocupacional (atividade profissional) específica e nem para o tamanho da propriedade.

O s clientes que se dedicam à bovinocultura apresentam nível de escolaridade significantemente maior, sendo a maioria dos clientes assíduos e reais proprietários rurais com propriedades com mais de 100 hectares. Q uanto aos clientes que praticam fruticultura, piscicultura e avicultura, observou-se que não apresentam diferenças quanto ao nível de escolaridade, condição ocupacional (atividade profissional) e tamanho deárea de propriedade, sendo estes clientes reais, em sua maioria.

Estes resultados indicam que a bovinocultura apresenta um comportamento diferenciado dos demais assuntos, sendo aconselhável, em termos de tomada de decisões futuras, haver maior aproximação com estes clientes do projeto Exagri, no sentido de ampliar o nível da informação disseminada, visto que o nível de escolaridade assim 0 permite. 
V erificou-se também, pelo emprego da análise de regressão, com $95 \%$ de nível de confiabilidade, que, quanto maior 0 nível de escolaridade, mais soluções são encontradas por meio dos A lertas Exagri, e, quanto maior a importância dada ao próprio uso do A lerta Exagri como fonte de informações, mais soluções são implementadase mudanças adotadas nas propriedades e atividades agrícolas, nos segmentos de clientes assíduos e reais.

0 assunto mais contemplado no A lerta Exagri foi horticultura, tendo sido contemplado 21 vezes no total dos A lertas. Este assunto teve 213 solicitações nos sete Alertas e continua sendo sugerido por 53 clientes pesquisados.

Em termos de soluções adotadas para problemas específicos, nas propriedades e atividades rurais, merecem destaque os seguintes assuntos: a) redimensionamento da saída de água dos tanques para piscicultura; b) replanejamento do espaçamento do plantio das mudas de acerola do sítio; c) utilização do modelo para silos de forragem; d) conservação e irrigação do solo para cultivo de hortaliças.

A lém de propiciar soluções para problemas específicos, os A lertas Exagri, segundo a opinião de um dos clientes assíduos, "vêm ajudando a mudar a maneira de pensar e agir dentro da sociedade, principalmente no que diz respeito à união entre os produtores para a realização de mudanças".

0 resultado dos pontos atribuídos ao A lerta Exagri, em uma escala de 0 (muito ruim) a 10 (muito bom), situou-se em nove, o que se aproximou da nota máxima. os principais benefícios esperados podem ser resumidos como segue: a) conter material de caráter social e de interesse comunitário voltado aos interesses das associações, sindicatos e cooperativas, bem como aos próprios agricultores, principalmente no aspecto referente ao êxodo rural, estimulando a permanência do homem no campo; b) fornecer assuntos sobre viabilidade econômica, retorno financeiro, custos, desenvolvimento autosustentado, administração da propriedade ou empresa rural e condições de mercado referentesà agropecuária; c) veicular informações sobre agriculturas alternativas e proteção de meio ambiente; d) oferecer um curso de atualização na área de economia agrária.

\section{GERAÇÃ O DE TEXTOS}

Considerando-se que as bibliotecas da Esal q/U SP têm um dos mel hores acervos do país na área de ciências agrárias, não foi difícil coletar eincluir na Base Exagri a literatura de interesse dos produtores etrabalhadores rurais, no primeiro momento do projeto. Entretanto, com a alimentação da Base, percebeu-se que boa parte desta literatura foi produzida antes de 1990, principalmente pelas unidades estaduais do Sistema Brasileiro de Extensão Rural (Sibrater), coordenado nacionalmente pela Empresa Brasileira de Extensão Rural (Embrater) e por diversas outras entidades governamentais e privadas do país. T udo parece indicar quea extinção da Embrater ea conseqüente crise nas unidades estaduais resultem em uma interrupção da produção de material extensionista no país, somente retomada alguns anos depois. Por outro lado, a prática dominante nas universidades e nas instituições de pesquisa agropecuária brasileiras privilegia a produção científica a ser veiculada em periódicostécnico-científicos internacionais e nacionais. D esta forma, a produção de publicações decaráter extensionista ainda é pequena. A ssim, o Projeto Exagri, percebendo esta demanda, implantou a Série Produtor Rural, cujo produto final são publicações produzidas por docentes e alunos da Esalq/USP, redigidase ilustradas de modo a tornar as informações acessíveis aos produtores e trabal hadores rurais, ao mesmo tempo em que servem como embrião de um processo gradativo de estímulo de ligação permanente entre a pesquisa e a extensão universitária na Esalq/USP. Esta série, a princípio, não constituía um objetivo específico do Projeto Exagri. Porém, a evolução do mesmo e a conscientização da comunidade técnica da Esalq/U SP nortearam esta ação.

A Série Produtor Rural foi lançada no início de 1997, tendo sido publicados, até o momento, nove números seqüenciais e um especial, com assuntos diversos na área agropecuária, sendo comercializados, com sucesso, pela DIBD/Esalq/U SP. O sclientes reaise assíduos do projeto, integrantes do grupo de controle, receberam todos os números desta s érie. O s títulos publicados até o momento são:

\section{C ultivo hidropônico de plantas (Q uiríno A C. C armello)}

2. Produção do cogumelo comestível pleurotus: opção promissora, especialmente na Região do V ale do Ribeira (Gilma L. Sturion \& M arcia R. T C. Ranzani)

3. C ultura do quiabeiro: técnicas simples para hortaliça resistente ao calor ( $K$ eigo $\mathrm{M}$ inami; Valéria $\mathrm{A}$ Modolo; A ntonio C. W Zanin \& João T essarioli N etto)

4. Rabanete- cultura rápida, para temperaturas amenas e solos areno-argilosos (K eigo M inami \& João T essarioli N etto) 
5. Cultura da mandioca para a Região C entro-Sul do Brasil (Gil M iguel S. Cámara \& Eduardo A M de O liveira)

6. C ultura da pupunha para produção de palmito ( $M$ arcelo $A$ N. N ishikawa; José R. M oro \& Gerhard Bandel)

7. Da piscicultura à comercialização: técnicas de beneficiamento do pescado deágua doce ( $M$ arília 0 etterer)

\section{C ultura da rúcula (K eigo M inami)}

9. Instalação de aplários (C arlos A.L. de Carvalho \& Luis Carlos M archini)

Número Especial - U tilização de reguladores vegetais na fruticultura, horticultura e plantas medicinais (Paulo R. C. Castro)

A snormas para publicação da Série Produtor Rural foram definidas pela DIBD/Esalq/USP, estando disponíveis aos interessados.

\section{EST RATÉGIAS DE COMUNICAÇÃO}

A s estratégias de comunicação em termos de promoção e distribuição do Projeto Exagri foram desenvolvidas no sentido de comunicar ao público a existência de um serviço de informação para produtores e trabalhadores rurais do Estado de São Paulo, desenvolvido pela DIBD/Esalq/USP.

Como primeira ação, por meio de mala direta, foi enviado um folder, com cartão-resposta, para as associações, cooperativas e sindicatos rurais, técnicos agrícolas, agrônomos, alunos, professores e pesquisadores universitários, bem como outras entidades da área de ciências agrárias do estado de São Paulo, com intuito de despertar 0 interesse e de medir a demanda inicial em assuntos agropecuários. A resposta ao folder foi representativa, servindo de apoio à geração de mailing list, que integra o cadastro da Base Exagri.

A ação visando a conscientizar a comunidade técnica agronômica da Esalq/USP foi efetivada por meio de visitas aos departamentos desta Escola, como forma de apresentar e promover o projeto, sendo que, nesta ocasião, foram entregues aos chefes destes departamentos 0 folder do Exagri e as normas para publicação na Série Produtor Rural.

A veiculação em jornais das organizações participantes foi outra ação de comunicação, sen do que merecem destaque as divulgadas no $\mathrm{C}$ anavieiro Paulista, jornal dos plantadores de cana da região de Piracicaba, que veiculou notíciassobre o Projeto de abril/maio de 1996 a janeiro/fevereiro 1998. T ambém os jornais locais das cidades de T ambaú, Leme, Casa Branca, Registro, M ogi M irim e Capivari, entre outras, veicularam notícias sobre o Projeto Exagri.
Cabe destaque ainda para a divulgação da revista A gropecuáriaH oje, com as matérias Biblioteca efetiva Projeto de Extensão, de julho/agosto de 1997 e Exagri: informação para produtores e trabalhadores rurais, de janeiro/fevereiro de 1996.

N a revista $\mathrm{G}$ lobo Rural, de fevereiro de 1998, também foi promovido o Projeto Exagri. 0 InfoU nir, informativo do Projeto Unir, o Boletim do Escritório de A tividades Internacionais da E salq/U SP e o Jornal da U SP divulgaram, da mesma forma, notícias do projeto.

A comunicação para os profissionais de informação da área de agricultura foi feita com a apresentação do projeto em forma de poster, no Seminário U SA IN /IA A LD Joint Conference - The Information Frontier: linking people and resources in a changing world, em Tucson, A rizona, USA, de 3 a 5 de abril de 1997. N esta ocasião, foi também realizada uma visita ao Rural Information Center - RIC/ NA L/USDA, em 8 e 9 de abril de 1997, em Beltsville, $M$ aryland, USA, no sentido de promover o que está sendo feito em termos de informação agrícola para produtorese trabalhadores rurais em São Paulo, Brasil, e ampliar o contato com os profissionais desta área, no exterior. Também no IAALD N ews, jornal da A ssociação Internacional de Especialistas em Informação e Documentação A grícola, de abril de 1996, constaram notícias sobre o Projeto.

Q uanto à Série Produtor Rural, a principal estratégia adotada foi a de enviar, simultaneamente, os números da Série Produtor Rural para o Programa Globo Rural, Suplemento A grícola do jornal 0 Estado de São Paulo e A grofolha. Como resultado, em um dos programas $\mathrm{G}$ lobo Rural foi levado ao ar o assunto Cultura do Q uiabeiro: técnicas simples para hortaliça resistente ao calor, que corresponde ao terceiro número desta série.

0 folder da Série Produtor Rural foi enviado às mesmas organizações e clientes potenciais que constam nomailing list do Projeto Exagri.

\section{AVALIAÇÃO DO PROJETO EXAGRI}

A lém das reuniões realizadas periodicamente com os dirigentes das organizações participantes, docentes da Esalq/U SP, assessores, consultores especial istas e outros, foram promovidos dois seminários para avaliação do projeto. 0 primeiro, em setembro de 1996, teve como tema a Dinamização e Integração do Projeto Exagri Participaram deste seminário, além da equipe do Exagri, as bibliotecárias da Esalq/U SP, dirigentes das organizações participantes do projeto, acompanhados de um produtor 
rural da sua região integrante do grupo de controle, bem como professores e alunos da Esalq/U SP.

Neste seminário, foi apresentada a palestra "A importância da Informação agrícola no desenvolvimento rural sustentável". 0 principal objetivo deste seminário foi o de levantar as situações favoráveise desfavoráveis do ambiente, os pontos fortes e fracos do projeto e os problemas a serem solucionados. Os participantes constituíram grupos de trabalhos heterogêneos.

Entre as conclusões do evento, algumas devem ser ressal tadas como de relevância:

1. há mobilização na Esalq/U SP para atender ao produtor rural;

2. o Projeto Exagri está modificando a cultura da própria Biblioteca da Esalq/USP;

3. os dirigentes das organizações estão orientando seus filiados para utilizar as facilidades e os serviços que o projeto está colocando à sua disposição.

O segundo seminário realizado em março de 1998 teve como tema a "Contextualização do Projeto Exagri no A mbiente da Informação A grícola Brasileira, Frente às N ovas T ecnologias".

Para este seminário, foram especialmente convidados profissionais da área de informação, com experiência na área de transferência da informação agrícola, além dos dirigentes das organizações participantes do projeto, da equipe do Exagri, dos consultores do Projeto e de alunose professores da Esalq/U SP.

Como dinâmica do evento, foi proferida palestra intitulada "A gente e U suário da Informação em Serviços de Extensão" e constituídos grupos de trabalhos para discussão de questões específicas, embasadas em documentos gerados pelo Projeto. 0 s grupos foram assim divididos: profissionais da informação e de dirigentes, alunos e professores da Esalq/USP.

A sconclusões do seminário voltaram-se, principalmente, para os seguintes pontos:

a) oferecer outras alternativas de serviços, tais como acesso a Base Exagri, via Internet e em CD-ROM , observandose a relação custo-beneficio, a relevância da informação utilitária e a transformação através do conhecimento, tendo em vista que o modelo atual está atendendo aos objetivos do Projeto Exagri. A s informações incluídas na Base Exagri poderão ser completadas com informações técnicas de outras bases disponíveisna Biblioteca da Esalq/
USP, bem como o recebimento de dados referentes a comercialização da produção, administração rural e de mercado;

b) desenvolver ações para motivar os produtores e trabal hadores rurais para leitura, taiscomo publicar textos curtos, bem ilustrados e em linguagem simples, sobre assuntos de interesse geral, procurando envolver a família rural e os jovens rurais;

c) divulgar os resultados de casos de produtores bemsucedidos e proceder à instalação de projetos pilotos de sucesso, como exemplificação.

Q uestões sobre a continuidade do Projeto Exagri também foram discutidas, tendo em vista que o prazo do projeto, três anos de duração, terminará em julho de 1998, acarretando conseqüentemente o fim dos recursos financeiros. Sua continuidade dependerá, basicamente, do acordo e do comprometimento das diversas parcerias para a consolidação do Projeto Exagri. A competência e as responsabilidades dos parceiros devem ser acordadas previamente. $\mathrm{H}$ averia possibilidade de cobrança de uma taxa de adesão para assegurar a produção de produtos e serviços de informação como A lertas Bibliográficos e cópias do material, empréstimo de material informacional, incluindo fitas de vídeo e levantamentos bibliográficos destinados ao pequeno e médio produtor rural, entre outros tipos de usuários.

Ficou evidente que a idéia do projeto está amadurecida, ainda que esta experiência não possa ser considerada acabada, pois o verdadeiro objetivo social do projeto é colocar à disposição informações que atendam às necessidades do pequeno e médio produtor e trabalhador rural brasileiro, tendo em vista a elevação do seu nível de renda e conseqüentemente de sua qualidade de vida.

Para os participantes, o projeto representou um avanço, uma mudança de filosofia de trabalho do profissional da informação. A tender ao produtor e ao trabalhador rural e não apenas ao pesquisador e/ou extensionista da área de ciências agrárias passou a ser uma realidade.

Para expandi-lo será necessário, antes de mais nada, consolidá-lo do ponto de vista da validade interna, atendendo às necessidades informacionais do produtor e trabalhador rural dasregiõesjá cobertaspelo Exagri para, posteriormente, ser disseminado em âmbito nacional, consideran do nesse processo as parcerias poten ciais. 0 protótipo do projeto, depois de colocado à disposição dos interessados, deverá sofrer adequações institucionais e regionais, quanto à sua metodologia, em função das características específicas do usuário final de cada região do país. 
Janeti L. B ombini de M oura / N ilce T . Puga-N ass / A mélia Silveira / Fernando A. da Silveira R ocha

No final do seminário, foram feitos diversos depoimentos pelos participantes, sendo que o de um dos usuários do grupo de controle parece bem representar o significado do Projeto para o trabal hador rural do estado de São Paulo: “... ainda vai chegar um dia em que eu quebrarei a gaiola e poderei estar divulgando tudo aquilo que eu aprendi eque vou aprender mais com o Projeto Exagri".

\section{AÇÕES FUTURAS}

Com base no desenvolvimento e na avaliação do Projeto, as seguintes ações deverão nortear a sua continuidade:

a) colocar disponível a Base Exagri na Internet, na home page da DIBD/Esalq/USP;

b) produzir CD-ROM a cada 5 mil registros compilados na Base Exagri;

c) desenvolver parcerias com entidades de produtores e trabalhadores rurais para, mediante pagamento de uma taxa de adesão, garantir o recebimento dos produtos de informação da D IBD/Esalq/U SP;

d) consolidar o projeto no estado de São Paulo;

e) expandir o protótipo do Projeto no âmbito nacional;

f) oferecer curso de economia agrária, na Esalq/U SP, para os dirigentes das entidades participantes no Projeto Exagri.

\section{CONSIDERA ÇÕ ES FINAIS}

0 presente relato mostrou as ações efetivadas nosúltimos três anos na DIBD/Esalq/USP, no sentido de disseminar informações em nível de extensão para os produtores e trabalhadores rurais do estado de São Paulo. T rata-se de uma iniciativa pioneira em muitos países em desenvolvimento, entre eles o Brasil. Informações de cunho extensionista que contribuam para a elevação da condição socioeconômica, cultural e tecnológica do produtor e do trabalhador rural do interior do estado de São Paulo são ainda iniciativas tímidas e muitas vezes isoladas, dependendo de grupos que se sensibilizam com este problema. Espera-se que o relato seja uma semente para que outras experiências possam ser iniciadas, objetivando elevação da qualidade de vida do brasileiro do campo.

Relato aceito para publicação em 14-11-2000

\section{A gradecimentos}

A gradecemos à Fundação W.K. Kellogg pelo apoio financeiro para o desenvolvimento desse projeto.

\section{BIBLIOGRAFIA CONSULTADA}

CROW DER, L.V. Marketing information systems for small-scale farmers. Information D evelopment, v. 13, n. 4, p. 179-183, 1997.

DIAZ BORDENAVE, J. A importância da informação agrícola no desenvolvimento rural sustentável. In: SEMINÁRIO DE DINAMIZAÇÃO E INTEGRAÇÃO DO PROJETO EXAGRI, 1., Á guas de São Pedro, SP, 1996. Á guas de São Pedro : [s. n., 1996].

ECHEGA RAY, M .A.A . de. A inovação tecnológica na Zona Rural de Goiás: estudo em dez municípios. Goiânia, 1995. 223p. Dissertação (M estrado) - Universidade Federal de Goiás. [Goiânia], 1995.

FERREIRA， J.R. 0 impacto da tecnologia da informação sobre o desenvolvimento nacional. C iência da Informação, Brasília, v.23, n. 1, p. 9-15, 1994.

FREIRE, I. A gente e usuário da informação em serviços de extensão. In: SEMINÁ RIO DE CONTEXTUALIZAÇÃO DO PROJETO EXAGRI NO AMBIENTE DA INFORMAÇÃO A GRÍCOLA BRA SILEIRA, FRENTE A S N O VA S TECNOLOGIAS, 1., São Pedro, SP, 1998. [s.l. : s. n., 1998].

HESSE, E. ; MOURA, J.L.B. Proposal of re-established a Latin A merican data base of agricultural information. In: IN TERAMERICA N PLAN N ING WORKSHOP FOR A GRICULTURA L INFORMATION TRA N SFER A ND NETW ORKING, W ashington, 1994. [s.l. : s. n., 1994].

JOH N, P.L. The Rural Information Center assists local communities. Library T rends, v. 41, n. 1, p. 153-175, 1995.

KISIL, M. Information age: less developed countries and the challenges in the relation between producers and users of information. In: USA IN/IA A LD JOIN T CONFEREN CE, Tucson, 1997. [s. I. : s. n.,1997].

MINISTÉRIO DA A GRICULTURA. Secretaria Geral. Centro N acional de Informação A grícola. Plano N acional de Informação e D ocumentação A grícola: 1986-1987. Braślia, 1988. 33p.

MOURA, J.L.B. ; PUGA-N A SS, N.T. Exagri project: availability and accessibility of agricultural information for small farmers in Brazil. In: USA IN/IA A LD JOINT CONFEREN CE, Tucson, 1997. [s. I. : s. n., 1997]. Poster.

O LIVEIRA , M .T. DE B. A ambiguidade da extensão rural universitária e as acusações dos técnicos. Revista de Economia e Sociologia Rural, v. 31 , n. 2, p. 103-124, 1993

QUEM EL, M.A.R. et al. Rede nacional de tran sferência e difusão de tecnologias apropriadas. Ciência da Informação, Brasília, v. 22, n. 3, p. 271-174, 1993.

REGION A L Plan for the Stablishment of an InterA merican Planning: workshop for information transfer and networking. W ashington, BID/N A L, 1994. (draft copy)

RURA L libraries and information services. Library Trends, v.44, n.1, p.1-219, Summer, 1995.

SA LIN A S B., L. La comunicacion escrita en divulgaciones agrícolas. In: FUNDAMENTOS de comunicacion científica e reddacción técnica: una recopilación. San José : IICA, 1988. p.125-151.

SCHLOTTFELD, C. D. Difusão de tecnologia e extensão rural na EM BRA PA : reflexões conceituais e práticas. Cadernos de Ciência e Tecnologia, v. 8, n. 1/3, p. 98-112, 1991.

TAGLIARI, P.S. A articulação pesquisa/extensão rural na agricultura. Florianópolis: EPA GRI, 1994. 82 p. (Documentos, 150).

UN ITED ST A TES DEPART MENT OF A GRICULTURE (W ashington). Information acess in rural america: January 1980 - A pril 1994. Beltsville : N ational A gricultural Library, 1994. 27 p. (Q uick bibliography series). 